\title{
Perceived Stress Levels and Support of Student Disability Services
}

\author{
Sarah Ardell $* \dagger$, Peter Beug*\$, Kayla Hrudka**
}

\begin{abstract}
Perceived stress of university students tends to be higher for students with disabilities compared to students without disabilities. Students with disabilities may therefore require campus support to manage additional stress they encounter. The current study investigated the relationship between students' perceived stress levels and enrollment in university campus Disability Services for Students (DSS). Three groups of university students were studied: those without disabilities ( $n$ $=42)$, those with disabilities registered with DSS $(n=21)$, and those with disabilities not registered with DSS $(n=23)$. Three hypotheses were tested. First, students with disabilities would have higher overall perceived stress levels compared to students without disabilities. Second, students with disabilities who were not registered with DSS would experience a higher level of perceived stress compared to students with disabilities who were registered with DSS. Third, students with disabilities registered with DSS would have a similar level of perceived stress to students without disabilities. Student participants completed an online self-report survey containing the Perceived Stress Scale(Cohen, Kamarck, \& Mermelstein, 1983). A one-way analysis of variance was conducted to investigate potential differences in perceived stress levels between the three groups. The results indicated that students with disabilities reported higher levels of stress compared to their peers without disabilities, yet DSS had no significant effect on perceived stress among students with disabilities. With these findings, we suggest that further research on the relationship between DSS and other academic factors, such as students' grade point average, should be conducted.
\end{abstract}

Keywords: perceived stress, university students, disability services, social support

Studies investigating challenges of post-secondary students with disabilities have identified obstacles specific to this population. Past literature articulates some of the most recognized obstacles for post-secondary students with disabilities. For one, students' self-reports suggest that attending a post-secondary institution can increase perceived stress and adversity (Arthur \& Hiebert, 2011). Since it generally has been conceded that individuals with disabilities experience more stress throughout their lifetime compared to individuals without disabilities (Heiman \& Precel, 2003), it is possible that students with disabilities may be more susceptible to increased levels of perceived stress while attending university or college. Second, an abundance of research has found that students with disabilities have unique struggles within academic and social spheres, such as higher stress, as compared to individuals without disabilities, which can impede their attainment of higher education (Hall, Spruill, \& Webster, 2002; Hartley, 2012; Heiman, 2006; Heiman \& Precel, 2003; Holloway, 2001; Lombardi, Murray, \& Gerdes, 2012). Third, studies acknowledge that to succeed in higher education, students must be resilient (Hall et al., 2002; Hartley, 2010; Hartley, 2012); that is, students must be able to overcome stressful and difficult situations. One important factor in

*Department of Psychology, College of Arts and Science, University of Saskatchewan, Saskatoon, SK, Canada

+Correspondence: sja378@mail.usask.ca

${ }^{\ddagger}$ All three authors contributed equally to the research and writing of this article 
resiliency is social support, which has been demonstrated as instrumental to success for many students who may be considered at risk of academic disadvantage (Hall et al., 2002; Hartley, 2010; Hartley, 2012). Without support, students with disabilities are at greater risk of struggling academically and may not succeed in higher education (Hartley, 2010).

Studies examining post-secondary students with disabilities have demonstrated a mixture of results relating to academic performance, academic achievement and perceptions of stress(Hall et al., 2002; Hartley, 2010; Heiman, 2006; Lyrakos, 2012). The support and accommodations provided to post-secondary students with disabilities must be evaluated as a result of the previously cited findings. In order to acquire more insight into the effectiveness of supports and services on perceived stress levels, the current study compared students with disabilities who have registered to received institutional accommodations with students who have disabilities and did not request institutional services that they are qualified to receive. In this study, we wanted to determine the potential level of impact that campus disability services, such as Disability Student Services (DSS) at the University of Saskatchewan, has on students' perceptions of stress.

\section{Literature Review}

Most students who choose to attend college or university believe it to be a place of opportunity, independence, and high achievement (Hartley, 2012). On the other hand, compared to high school, higher education is filled with high academic expectations, more distant instructors and social supports compared to high school, and an undergraduate culture that gravitates toward excessive drinking and drugs (Hartley, 2012; Janusis \& Weyandt, 2010), all while being highly competitive and academically demanding (Hartley, 2012; Heiman, 2006; Heiman \& Precel, 2003). Consequently, many students' perceived stress levels tend to increase after enrolling in a post-secondary institution (Hartley, 2012). Arthur and Hiebert (2011) found that students' main concerns in higher education were related to the courses offered that were perceived as highly challenging and compact. For such students, stress was often the result of their persistent efforts required to meet the academic demands placed on them.

In higher education, stress can be detrimental to academic success for students with disabilities (Heiman \& Precel, 2003).Students who are dealing with stress often are experiencing symptoms of fatigue, headaches, depression and anxiety, and many have difficulties coping during midterms and finals (Heiman \& Precel, 2003). As suggested, simply having a disability puts a person at risk for experiencing stress (Hall et al., 2002; Heiman, 2006; Lombardi et al., 2012). It is therefore particularly important that these stressors be managed or lessened for students with disabilities in order to ensure equal opportunities to obtain academic education and success.

Students with disabilities report greater perceptions of academic-related stress than students without disabilities (Heiman, 2006; Heiman \&Precel, 2003; Holloway, 2001; Lombardi et al., 2012). Academic stress is increased due to the need to spend greater time and effort to complete academic tasks in comparison to those without disabilities. In a study conducted by Heiman and Precel (2003), college students with learning disabilities (LDs) reported higher levels of stress during exams than their peers without LDs. Stress-related symptoms such as feelings of frustration, anxiety, helplessness, and doubt in relation to academic performance were also reported (Heiman \& Precel, 2003). In addition, students with disabilities who did not complete their degree commonly reported high levels of perceived stress (Murray, Lombardi, Bender, \& Gerdes, 2013) and lack of support (Hartley, 2010) as reasons for their discontinuance of higher education.

Students with disabilities show greater difficulties related to academic adjustment (Hall et al., 2002; Lombardi et al., 2012; Murray et al., 2013) and may be less academically prepared (Hall et al., 2002). Compared to students without disabilities, many students with disabilities require more time to learn new information, must apply greater effort for understanding and completing school projects, and tend to apply unconventional learning strategies (Heiman \& Precel, 2003) that can require extra time and effort. For example, students with disabilities tended to be better visual learners, but struggled to study with written words compared to their peers without disabilities (Heiman \& Precel, 2003).

In some cases, academic-related challenges have been reflected in the differences of academic performance between students with disabilities and students without disabilities. The majority of research data in both Canada and the United States indicates that students with disabilities tend to have low rates of post-secondary attendance (Hall et al., 2002), higher attrition rates (Hartley, 2010; Hartley, 2012; Heiman, 2006; Murray et al., 2013), lower grade point averages (Janusis \& Weyandt, 2010; Murray et al., 2013), and lower graduation rates from university or college compared to their peers without disabilities (Murray et al., 2013).

Research regarding differences in perceptions of stress and academic performance between students with and without disabilities is inconsistent. For example, Jorgensen et al. (2007) found no difference in perceived levels of stress among students with and without 
disabilities. In other studies, students with disabilities achieved equivalent or even higher academic averages in post-secondary institutions compared to their peers without disabilities (Hall et al., 2002; Heiman \& Precel, 2003; Jorgensen et al., 2007). By contrast, Heiman (2010) found that students with LDs reported higher academicrelated stress. In regards to academic performance, Murray, Goldstein, Nourse, and Edgar (2000), as well as Wessel, Jones, Markle, and Westfall (2009), found that students with disabilities performed poorly in their academics compared to their peers without disabilities.

In order to understand the inconsistencies within the literature, it may be important to look at other factors that may be influencing the success or failures of students with disabilities. The literature on post-secondary achievement for students with disabilities highlights the concept of resiliency. Resiliency is defined as a person's persistence and ability to face challenges and reduce the associated stress of those challenges (Hartley, 2012). It has been suggested that protective factors are crucial for resiliency in post-secondary education (Hall et al., 2002). Protective factors include internal characteristics (e.g., social skills) and external characteristics (e.g., social support) (Hall et al., 2002; Hartley, 2012). Social supports specifically are some of the most effective external protective factors (Hall et al., 2002; Hartley, 2010). Therefore, ensuring social supports may be the difference between success and failure for many of the students with disabilities.

Campus Disability Services (CDS), such as DSS, offer a wide range of services and accommodations for postsecondary students with disabilities (Hartley, 2012; Holloway, 2001; Murray et al., 2013). The most common supports provided by CDS are academic advisors and resources assisting with mastering different learning techniques (Saskatchewan, 2015). It has also been suggested that reliance on institutional supports in postsecondary education is more necessary than other social supports since students may lack other social supports (Lombardi et al., 2012). For example, many students leave home to attend higher education, and may not have a lot of time to keep in close contact with familial social supports while studying during the academic year. It may also be argued that social supports within the academic setting will be more effective for academic-related needs.

The quality and variety of support services offered by post-secondary institutions may contribute to students' overall performance outcomes and academic-related stress. For example, a study that ran for 12 years in a Quebec college found that both academic performance and success in terms of attaining a post-secondary degree was no different among students with disabilities and students without disabilities (Jorgensen et al., 2007). It was noted that students reported satisfaction with the services they received within their institution. In a study by Murray et al. (2013), high satisfaction of educational supports was found to be important for assisting post-secondary students with disabilities in academic adjustment (Murray et al., 2013), which may potentially help their overall academic success. Social support is necessary for students at risk of failing to succeed and helps them adjust to the demands of higher education (Heiman, 2006). Heiman (2006) suggested that students with disabilities perceive having fewer social supports compared to students without disabilities, and these students were more likely to attribute academic failure to the lack of supports they have.

It should also be recognized that many students who are enrolled in post-secondary institutions with disabilities are not registered with educational and social supports (Jorgensen et al., 2007). This may be the case for several reasons. Heiman (2006) suggests that several students with disabilities have delayed cognitive development, and therefore they may not recognize their own needs or feel that accommodation is necessary for them. Students have also reported that the process of seeking and receiving accommodations can be stress inducing (Holloway, 2001). The process often includes visits with physicians, requesting documentation, and needing to request accommodations and services from their institution (Holloway, 2001). In addition, students with disabilities are also responsible for ensuring they are given these accommodations by their professors (Heiman, 2006; Lombardi et al., 2012). Anecdotal reports from students with disabilities suggested that many feel stress having to approach staff, students, and professors (Holloway, 2001) in regards to their disability. Therefore, some wish to avoid the stigma of being a student with a disability by avoiding the services provided, or avoiding asking professors for these accommodations (Holloway, 2001).

There is limited research examining perceptions of academic-related stress among students with disabilities. As suggested by Hartley (2012), resiliency and perceived stress are negatively associated, and according to Hall et al. (2002) and Hartley (2010), an important factor of resiliency is social support. Therefore, achievement of personal academic goals and degree attainment depends on institutional supports to be effective for reducing stress for students with disabilities. It should be noted that not all studies have illustrated the benefits of social support (Janusis \& Weyandt, 2010); however, the research so far has only compared students without disabilities to students who are registered in DSS. There is limited research examining students with disabilities who are not registered to receive institutional services or accommodations. By examining this third population, we may gain greater 
insight into the role DSS plays in students' academic lives and particularly, their perceived stress.

Particularly of interest, we wished to determine the potential impact DSS has on post-secondary students' perceived stress levels. We not only compared perceived stress levels of students without disabilities to students with disabilities registered with DSS, but we further assessed perceived stress among students with disabilities who chose not to register with DSS for accommodations and support. Three main hypotheses for the current study were made. First, we hypothesized that students with disabilities would experience higher levels of perceived stress compared to their peers without disabilities. Second, given the extensive supports and services offered to students registered with DSS, we expected that among students with disabilities, those who were registered with DSS would experience lower levels of perceived stress compared to those who are not registered with DSS. Lastly, we predicted that accommodations and services provided by DSS would be adequate for relieving additional stressors, and therefore, we expected that students with disabilities registered with DSS would have similar levels of perceived stress to students without disabilities.

\section{Method}

\section{Participants}

Our participant sample consisted of full-time undergraduate and graduate students currently attending a post-secondary institution. Only enrolled full-time students were considered as prior research demonstrates varying university experiences between full and part-time student enrollment status (Kember, Lee, \& Li, 2010). One hundred and one students participated in the study; the data for 14 of those students were excluded from analysis because of their part-time student status. No incentive for participation was provided.

For participants to be included in the disability category, they were given the option to self-declare as having one of the disabilities that are eligible for registration with the University of Saskatchewan campus disability services. Eligible disabilities included ADHD, Autism Spectrum Disorder, brain injuries, chronic health issues, deafness, learning disabilities, mental health issues, mobility issues, and low vision (Saskatchewan, 2015). Each of these disabilities was defined with only the name of the disability. The group with no disabilities had the most participants $(n=43)$, followed by students not registered in DSS $(n=23)$ and students registered in DSS $(n=21)$.

The representations of the disabilities had by people who participated in the study are as follows: mental health disorders(35.6\%), ADHD (16.1\%), chronic health issues $(11.5 \%)$, and remaining disabilities (14.8\%)(Figure 1 ).

The majority of participants were in their third year (26.4\%) while fourth year (25.3\%) and second year (18.4\%) students were second and third most frequently represented, respectively (Figure 2 ).

For participants categorized as having a disability and being registered in DSS, $22.7 \%$ responded that they registered for DSS in their first year, first semester and $18.2 \%$ registered prior to their first year of university. There was a large increase of participants who registered for DSS in their third year (27.3\%) (Figure 3).

We recruited participants through several online and offline sources. These consisted of advertisements promoting the study posted on the authors' Facebook pages, the University of Saskatchewan's (2015) Disability Services official blog and Twitter page, and the University of Saskatchewan's online bulletin board. Other members of the psychology research lab courses were recruited through a letter of invitation through email. In addition, posters were set up around the University of Saskatchewan campus.

\section{Measures and Procedure}

Participants completed a short demographic questionnaire and the Perceived Stress Scale (PSS) by Cohen, Kamarck, and Mermelstein (1983). The demographic survey consisted of questions regarding participants' full-time university student status, year of study, and disability status. If the participant indicated they had a disability they were given the option to answer follow-up questions on the type of disability, their registration status in DSS, and year of registration in DSS.

Participants then completed the PSS, which consists of 14 questions regarding the participants' own 
Figure 1: A bar graph, representing percentage (\%) of disabilities of the sample population with each type of disability

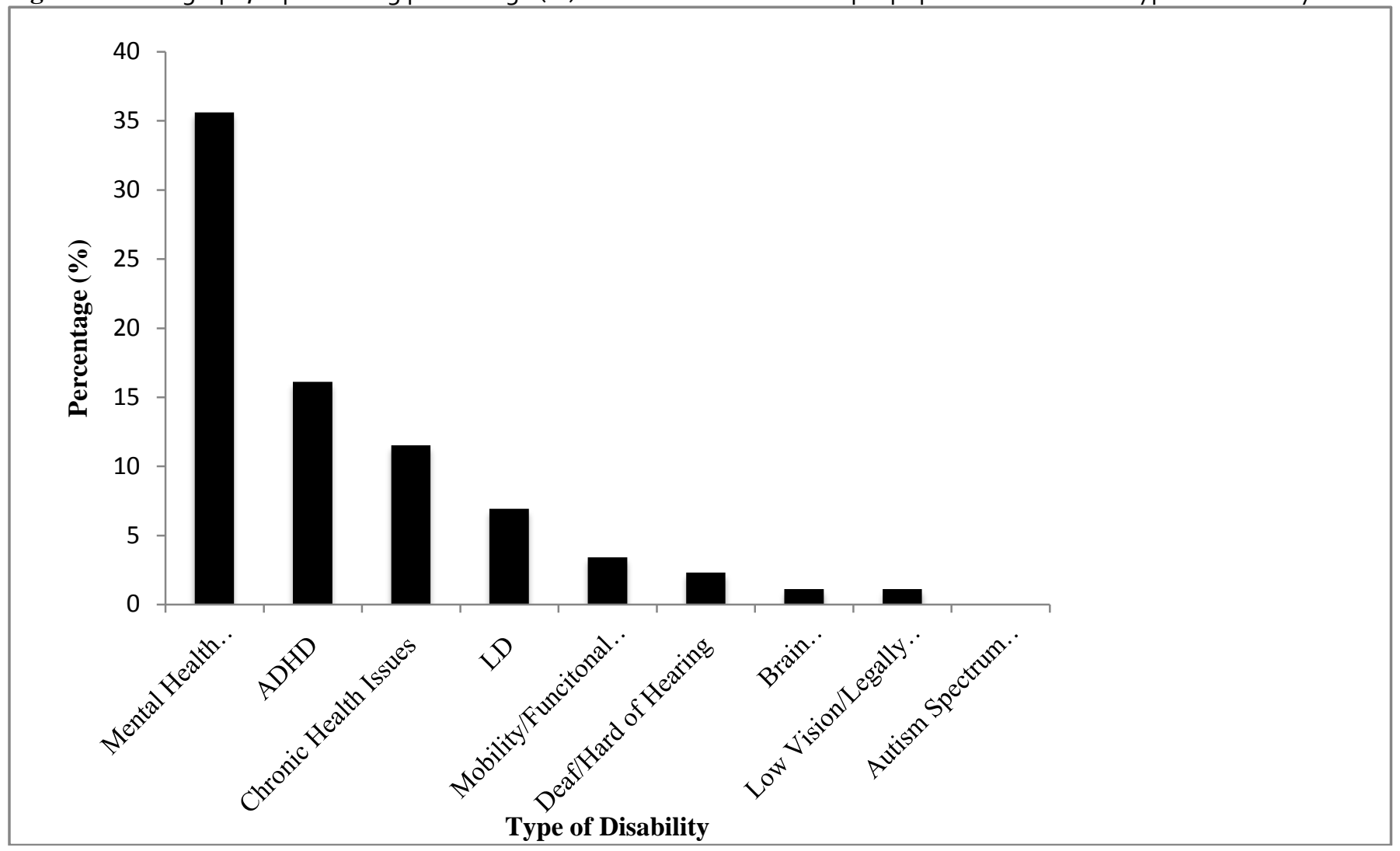

interpretation of daily stress and coping mechanisms. The PSS included questions such as "In the last month, how often have you found that you could not cope with all the things that you had to do?" Seven items on the scale were reverse scored. Participants answered the questions using a 5-point Likert-type scale with answers ranging from 1 (Never) to 5 (Very Often). The participant's composite score of perceived stress was the summation of responses to all 14 items of the scale. The internal reliability was a Cronbach's Alpha of .881. This is considered an adequate internal reliability, meaning the items in the scale correlated well with each other. In a meta-analysis of the psychometric properties of the PSS the 14-point PSS was found to have a Cronbach's Alpha of at least .7 in 11 out of the 12 studies examined (Lee, 2012). The internal reliability in our study is consistent with other studies using the 14-point PSS.

Participants accessed the survey through a public link to retain participant anonymity. The lead capture page of the survey consisted of a consent form. After providing consent the participants filled out the demographic questionnaire, followed by the PSS. The last page of the survey consisted of a debriefing form including an explanation of the materials, purpose of the study, and information on campus disability services and student counseling services.

\section{Results}

The three hypotheses examined in this study were as follows: (a) the group of participants with disabilities not registered with DSS would experience a higher level of stress than the group of participants with disabilities registered in DSS,(b)all participants with disabilities would have a higher overall perceived stress level than participants without disabilities,(c)the group of participants with disabilities registered in DSS would have a similar level of perceived stress to participants with disabilities.

Data collection took place from February $23^{\text {rd }}$ to March $9^{\text {th }}, 2015$. Descriptive statistics were performed on the perceived stress levels of the three groups, the frequency of disabilities represented, and the year of registration in DSS.

IBM's SPSS software was used to analyze the data. The participants' perceived stress score was obtained by summing the responses of the PSS. We conducted a oneway between subjects analysis of variance (ANOVA) to look 
Figure 2: A bar graph, representing the percentage of current academic year of participants

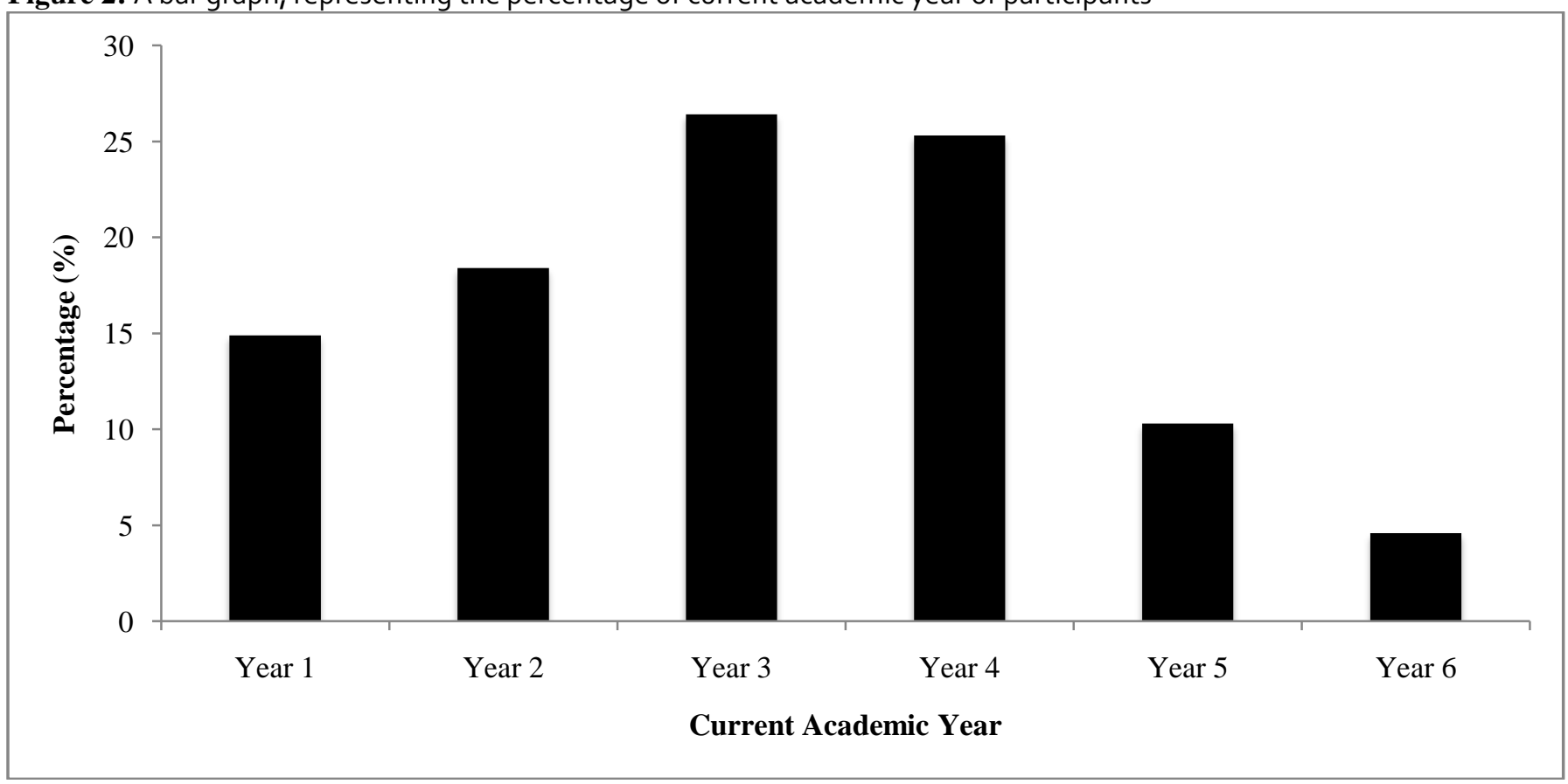

for significant differences in perceived stress between the groups. The results of the ANOVA showed a significant difference in perceived stress $F(2,84)=33.362, p<.001$.

Due to the significant difference found in the ANOVA, a Tukey HSD post-hoc test was implemented. A significant difference in perceived stress was found between the students with disabilities and students without disabilities. Students with disabilities registered in DSS $(M=48.80, S D$ $=5.92)$ and students with disabilities not registered in DSS $(M=48.52, S D=6.45)$ were found to have significantly higher levels of perceived stress than students without disabilities $(M=37.37, S D=6.67)$ at $p<.001$. This indicates that perceived stress was higher for students with a disability than for students without a disability, supporting our second hypothesis. No significant difference found, however, between the group with disabilities registered with DSS and the group not registered with DSS $(p=.988)$, contradicting the first hypothesis. Similarly, the third hypothesis was not supported, as the perceived stress levels of the group of participants with no disabilities and the group of participants with disabilities registered with DSS were significantly different (Figure 4).

\section{Discussion}

The ultimate goal of this study was to determine how the perceived stress levels of students with disabilities in higher educational institutions are influenced by accommodations and social supports provided through campus disability services, such as the University of Saskatchewan's Disability Services for Students (DSS). Although interesting results were found, they may indicate that services provided by DSS are inadequate to meet the needs of the students who utilize their services. Although it was observed that students with disabilities experience greater levels of perceived stress than students without disabilities (Hall, Spruill, \& Webster, 2002; Heiman, 2006; Heiman \& Precel, 2003; Holloway, 2001; Lombardi et al., 2012), it was also observed that students with disabilities registered with DSS did not differ in perceived stress levels in comparison to those not registered in DSS. Additionally, the students with disabilities registered in DSS did not have similar levels of stress to those who do not have disabilities.

The results were unexpected as DSS was anticipated to act as a form of social support through its services (Lombardi, Murray, \& Gerdes, 2012), lessening the perceived stress of the students. The expected results were not observed as the perceived stress for those in the group of participants with disabilities registered in DSS was not relieved.

The lack of reduced perceived stress levels may be explained through studies by Heiman (2006, 2010). In Heiman's (2006) study, differences in stress levels were isolated to individuals with LDs; those without LDs had lower perceived stress levels than those with LDs. Because the percentage of disabilities categorized as mental health disorders (35.6\%) is of higher percentage than LDs (6.9\%) in 
Figure 3: A bar graph, representing the year of registration in DSS of participants in the group of participants with disabilities registered in DSS category

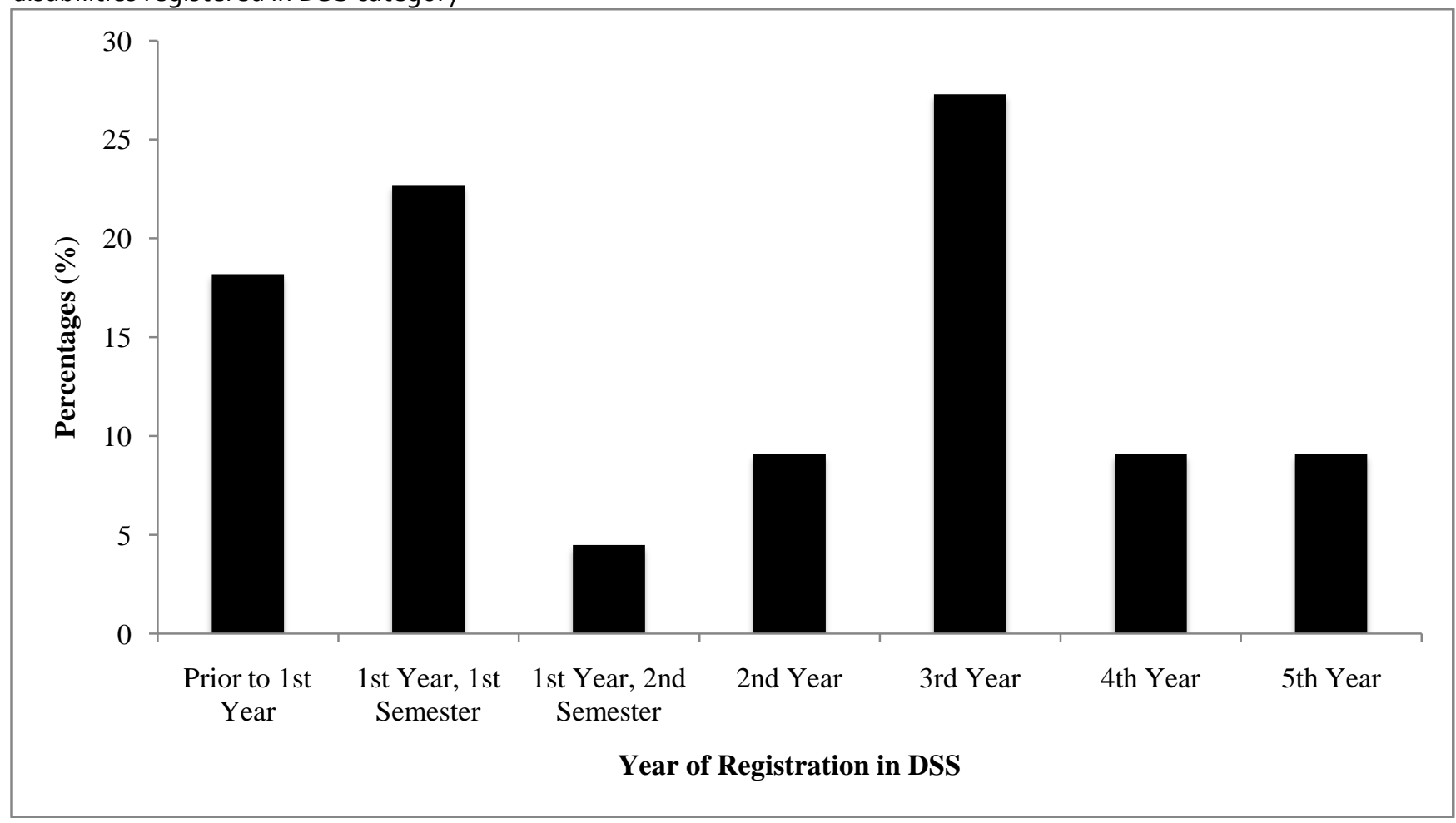

the current study, the results may be swayed, as LDs are not equally represented (see Figure 2). Future study may benefit from having equal numbers of participants in each disability type so they can be equally weighted when conducting analysis. Equating the groups may allow for greater determination of which disabilities DSS decreases perceived stress levels and/or do not decrease the perceived stress levels of students. Varying disabilities require different learning accommodations; therefore, by increasing and equating the number of participants in each category, there will be a greater ability to provide a thorough evaluation of the accommodations DSS has for each disability.

The influence DSS has on students with disabilities may be better understood in a longitudinal-type study utilizing a more comprehensive, qualitative measure of stress. Observing the same student before and after their admission to DSS, and over several years may demonstrate different results in their perceived stress. In addition, investigating other aspects such as students' grade point average (GPA) may provide evidence for the positive influence DSS may have on students' academic experience. Previous research has shown lower academic performance for individuals with disabilities, as they are especially vulnerable to having academic difficulties (Reiff, Hatze, Bramel, \& Gibbon, 2001; Lombardi et al., 2012; Trammel,
2014). Therefore, DSS may have a greater effect on academic performance of students with disabilities rather than their overall perceived stress level.

Due to the previously mentioned results in this study, DSS was not found to act as a form of social support adequate to decrease the levels of perceived stress among students with disabilities. A decline in the perceived stress levels among students in the group of participants with disabilities registered in DSS was not demonstrated, even though prior research indicates that social support is a buffer for levels of perceived stress (Hartley, 2012; Heiman, 2006; Holloway, 2001; Lombardi, et al., 2012; Lyrakos, 2012; Murray et al., 2013). Therefore, further research would increase the understanding of the positive impact DSS currently has on students with disabilities and to discover how it can improve the services currently available to the students.

This current study has several limitations to be improved upon in the future. Firstly, the sample was selfselected. Students who did not participate in the study may significantly differ from the students who did participate. Secondly, the study lacked a demographic question determining which university the participants attended, resulting in unknown location of participants. It also lacked a question asking how often and what accommodations participants utilized DSS for. The lack of these questions 
Figure 4: A bar graph, representing the mean score on the Perceived Stress Scale (PSS) of each of the three groups. The three groups are the different statuses of disability or registration in Disability Services for Students (DSS). The standard error for each group is represented by the error bars in each column.

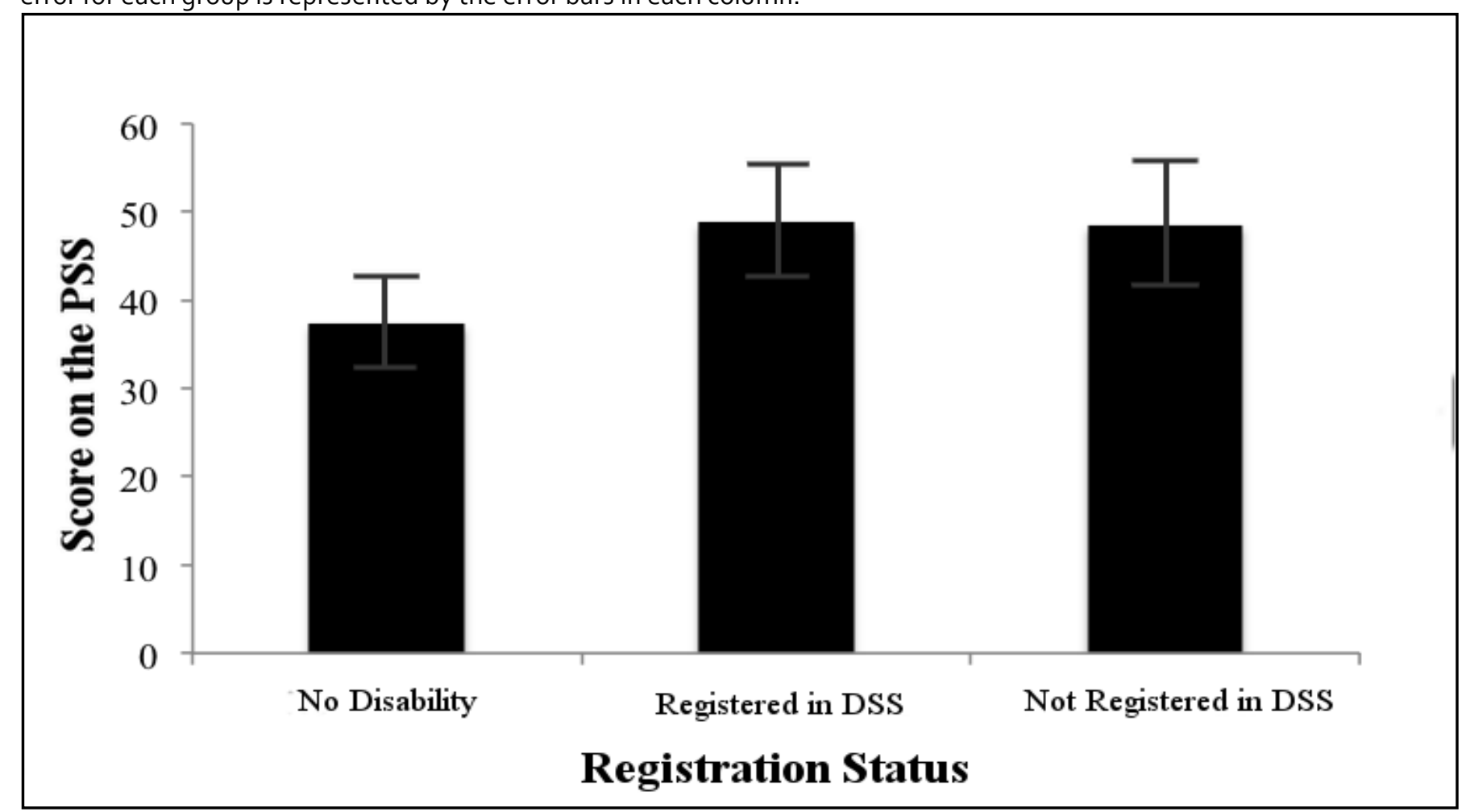

aided in participant anonymity but hindered the analysis of results. A demographic question would have allowed comparison between campuses and the success of the services they offer. Universities and colleges could then learn from one another in how to support students with disabilities. Additionally, the demographic questionnaire lacked a question indicating how much students with disabilities utilized DSS. Such a question would have allowed for understanding whether the students failed to have decreased perceived stress levels due to underutilization of DSS, rather than a lack of services available to students.

Finally, increasing the number of participants and equating disability types in each category would allow the difference between disability types to be accounted for and represented in the study, allowing for greater validity during interpretation of results. Due to the confidential nature of DSS, we were limited in our ability to interpret how the students with disabilities in this study represented the total number of individuals registered in DSS. Future study may benefit from being able to identify how the sample reflects those registered in CDS as an entirety.

The results of this study indicate that DSS is not an adequate support to decrease the perceived stress of students with disabilities. Future study and program evaluation of DSS is needed in order to fully understand how to best support students with disabilities through DSS, and to understand the role DSS currently in the lives of students with disabilities.

\section{Acknowledgements}

Thanks to Michel Desjardins, Linzi Williamson, and especially Melanie Bayly for their support, critique, and guidance throughout the duration of this research project. 


\section{References}

Arthur, N., \& Hiebert, B. (2011). Coping with transition to post-secondary education. Canadian Journal of Counselling and Psychotherapy/Revue canadienne de counseling et de psychothérapie, 30(2), 93-103. Retrieved fromhttp://www.cjcrcc.ucalgary.ca/cjc/index.php/rcc/article/view/101 6

Cohen, S., Kamarck, T., \& Mermelstein, R. (1983).A global measure of perceived stress. Journal of Health and Social Behavior,24(4), 385-396. Retrieved from http://www.jstor.org/stable/2136404

Hall, C. W., Spruill, K. L., \& Webster, R. E. (2002). Motivational and attitudinal factors in college students with and without learning disabilities. Learning Disability Quarterly, 25, 79-86. doi:10.2307/1511275

Hartley, M. T. (2010). Increasing resilience: Strategies for reducing dropout rates for college students with psychiatric disabilities. American Journal of Psychiatric Rehabilitation, 13(4), 295-315. doi:10.1080/15487768.2010.523372

Hartley, M. T. (2012). Assessing and promoting resilience: An additional tool to address the increasing number of college students with psychological problems. Journal of College Counseling, 15(1), 3751. doi:10.1002/j.2161-1882.2012.00004.X

Heiman, T. (2006). Social support networks, stress, sense of coherence and academic success of university students with learning disabilities. Social Psychology of Education, 9(4), 461-478. doi:10.1007/s11218-006-9007-6

Heiman, T., \& Precel, K. (2003). Students with learning disabilities in higher education academic strategies profile. Journal of Learning Disabilities, 36(3), 248-258.

doi:10.1177/002221940303600304

Holloway, S. (2001). The experience of higher education from the perspective of disabled students.Disability \& Society, 16(4), 597615.doi:10.108o/og687590120059568
Jorgensen, S., Fichten, C. S., Havel, A., Lamb, D., James, C., \& Barile, M. (2007). Academic performance of college students with and without disabilities: An archival study. Canadian Journal of Counselling and Psychotherapy/Revue canadienne de counseling et de psychothérapie, 39(2), 101117. Retrieved from http://search.proquest.com/docview/195800257? accountid=14739

Janusis, G. M., \& Weyandt, L. L. (2010). An exploratory study of substance use and misuse among college students with and without ADHD and other disabilities. Journal of Attention Disorders, 14(3), 205-215. doi:10.1177/1087054710367600

Kember, D., Lee, K., \& Li, N. (2010). Cultivating a sense of belonging in part-time students. Interntional Journal of Lifelong Education, 20(4), 326-341. doi: $10.1080 / 2601370117754$

Lee, E. H. (2012). Review of the psychometric evidence of the perceived stress scale. Asian Nursing Research, 6(4), 121-127. doi:10.1016/j.anr.2012.08.004

Lombardi, A. R., Murray, C., \&Gerdes, H. (2012). Academic performance of first-generation college students with disabilities. Journal of College Student Development, 53(6), 811-826. doi:10.1353/csd.2012.0082

Lyrakos, D. G. (2012).Impact of stress, social support, self-efficacy, and coping on university students, a multicultural European study. Scientific Research, 3(2), 143-149. Retrieved from: http://dx.doi.org/10.4236/psych.2012.32022

Murray, C., Goldstein, D. E., Nourse, S., \& Edgar, E. (2000). The postsecondary school attendance and completion rates of high school graduates with learning disabilities. Learning Disabilities Research \& Practice, 15(3), 119127.doi:10.1207/SLDRP1503_1

Murray, C., Lombardi, A., Bender, F., \& Gerdes, H. (2013). Social support: Main and moderating effects on the relation between financial stress and adjustment among college students with disabilities. Social Psychology of Education, 16(2), 277-295. doi:10.1007/s11218-012-9204-4 
Reiff, H. B., Hatzes, N. M., Bramel, M. H., \& Gibbon, T. (2001). The relation of $L D$ and gender with emotional intelligence in college students. Journal of Learning Disabilities, 34(1), 6678.doi: 10.1177/002221940103400106

University of Saskatchewan. (2015). Disability Services for Students. Retrieved February 4, 2015, from University of Saskatchewan Students: http://students.usask.ca/health/centres/disability -services-for-students.php\#Registration 
Perceived Stress and Disability Services (Ardell) 